\title{
Pressure swing absorption of carbon dioxide in n-methyl-2-pyrrolidone so- lutions
}

\author{
Hanna Kierzkowska-Pawlak \\ Faculty of Process and Environmental Engineering, Technical University of Lodz, ul. Wólczańska 213, 90-924 Łódź, \\ Poland, kierzkow@p.lodz.pl, fax +426368133
}

\begin{abstract}
The mass transfer rates during $\mathrm{CO}_{2}$ absorption and desorption from $\mathrm{N}$-methyl-2-pyrrolidone solutions were measured at $293.15 \mathrm{~K}$ in a baffled agitated reactor with a flat gas-liquid interface. Based on the measured values of pressure changes, the desorption rate was determined and compared to the absorption rate at the same driving force. Two distinct mechanisms of desorption were observed. The transition from bubbling to the diffusive desorption is found to be a function of the supersaturation ratio, pressure and the stirring speed.
\end{abstract}

Keywords: $\mathrm{CO}_{2}$ separation, bubbling desorption, supersaturation ratio.

Presented at VII Conference Wasteless Technologies and Waste Management in Chemical Industry and Agriculture, Międzyzdroje, 12 - 15 June, 2007.

\section{INTRODUCTION}

The dominant industrial process for the separation of acid gases such as $\mathrm{CO}_{2}$ and $\mathrm{H}_{2} \mathrm{~S}$, from industrial and natural gas streams is absorption by different solvents. Another important application of absorption-based technologies is $\mathrm{CO}_{2}$ separation from flue gases at power plants. The idea of carbon dioxide sequestration which includes its capture and storage in the underground rock formations has progressed steadily over the past ten years. It is claimed that this solution could play an important role in solving the problem of the increasing greenhouse gas emissions. The physical or chemical absorption of $\mathrm{CO}_{2}$ are generally recognized as the most efficient post-combustion $\mathrm{CO}_{2}$ separation technologies at present. The most commonly used physical solvents are methanol at low temperatures (Rectisol process), propylene carbonate (Fluor process), N-methyl-2-pyrrolidone (Purisol process) and dimethyl ether of polyethylene glycol (Selexol process) ${ }^{1}$. The common feature of these processes is that they are used in the absorber-stripper mode, requiring two separate steps in $\mathrm{CO}_{2}$ separation. This technology is known as a pressure swing absorption process where low pressure is used to desorb the $\mathrm{CO}_{2}$ and regenerate the solvent. Although in many practical situations the operational and capital costs of the desorption column may be greater than that of the absorption column, the studies devoted to desorption are not as numerous as those concerning absorption and there is little information in the literature on the design aspects of desorption columns. The problem of predicting the desorption rates arises when the process is accompanied by bubble nucleation in the liquid bulk. This phenomenon completely changes the hydrodynamic conditions in the liquid phase and the diffusive mass transfer equations cannot describe the process rate in a way analogues to absorption.

Researches on measuring and the calculation of the desorption rate in the typical desorption apparatus are very limited as compared to the theoretical considerations of bubble nucleation from the supersaturated liquid solutions ${ }^{2}$. Only a few references report quantitative results on the rates of physical gas desorption accompanied by bubble nucleation from the agitated liquid. Weiland et al. ${ }^{3}$ investigated the desorption of $\mathrm{CO}_{2}$ from the supersaturated water solutions using a stirred cell apparatus. Hikita and Konishi ${ }^{4}$ studied the same gas-liquid system in a baffled agitated vessel operated in a continuous manner. Recent literature sources contain no references to the problems under consideration.

The main scope of the present paper is therefore to develop a reliable method for performing the experiments of a gas desorption from the supersaturated solutions initialized by the pressure release. The validity of the proposed technique was tested on a well known $\mathrm{CO}_{2^{-}}$ water system. Some preliminary results on $\mathrm{CO}_{2}$ desorption rates from $\mathrm{N}$-methyl-2-pyrrolidone $\left(\mathrm{C}_{5} \mathrm{H}_{9} \mathrm{NO}\right)$ solutions are presented at $293.15 \mathrm{~K}$ for various initial supersaturation ratios. Additionally, the experimental method allows to determine the equilibrium $\mathrm{CO}_{2}$ solubility and enthalpy of absorption and desorption.

\section{EXPERIMENTAL}

Apparatus. The measurements were performed in the heat flow reaction calorimeter (Chemical Process Analyser, ChemiSens AB, Sweden) which is a fully automated and computer-controlled stirred reactor vessel with the possibility of an on-line measurement of thermal power developed by the process. Its heart is a mechanically agitated stainless steel/glass reactor with an effective volume of $250 \mathrm{~cm}^{3}$. The reactor was equipped with four baffles and an impeller stirrer. While in use it is submerged in the thermostating liquid bath. A Peltier element mounted inside the bottom of the reactor serves as an efficient heating and cooling device and keeps the temperature constant to $\pm 0.1 \mathrm{~K}$.

Procedure. Each experiment consisted of two steps including the absorption and subsequent desorption initialized by the pressure release. The schematic diagram of an experimental set-up is shown in Fig. 1. The solvent in the amount of $100 \mathrm{~cm}^{3}$ was placed into the reactor. The liquid was then degassed under vacuum. When the vacuum was shut off, the system was allowed to come to vapour liquid-equilibrium at $293.15 \mathrm{~K}$ under the stirring conditions. At this equilibrium, the stirring was stopped for a moment and the gas was introduced during a short time 
to the upper part of the cell until an arbitrary pressure was reached, which was recorded as the initial pressure $\left(\mathrm{P}_{\mathrm{i}}\right)$. Then the process was initiated by switching on the stirrer at the desired mixing speed. Pressure decay versus the time was recorded as a result of the $\mathrm{CO}_{2}$ absorption through the horizontal gas-liquid interface until the equilibrium state was reached $\left(\mathrm{P}_{\mathrm{f}}\right)$. This total pressure change from the initial to the final value $\left(\mathrm{P}_{\mathrm{i}}-\mathrm{P}_{\mathrm{f}}\right)$ was necessary for calculating the equilibrium $\mathrm{CO}_{2}$ solubility in the liquid.



Figure 1. Experimental set-up: $\mathrm{N}_{\mathrm{s}}$, stirring speed transducer; $\mathrm{T}$, temperature sensor in the reactor; $\mathrm{P}$, pressure transducer; q, heat flow transducer

The desorption run was conducted in the similar manner. The stirring was stopped for a moment while the pressure was manually released by adjusting the exit valve. The resulting pressure drop in the reactor imposed the required supersaturation on the system and subsequently led $\mathrm{CO}_{2}$ to release from the liquid. The corresponding pressure increase was recorded, up to another gas-liquid equilibrium value. The measurement of the rate of gas pressure rise was then related to the rate of desorption with respect to time.

All the experiments were carried out at $293.15 \mathrm{~K}$. Various stirring speeds were applied: 150, 200, $250 \mathrm{~min}^{-1}$. The pressure change in the absorption or desorption run was in the range of (0.1 to 1$) \mathrm{MPa}$. The pressure was measured by means of an IDA transducer (Nobel Electronik) with the accuracy of $0.005 \mathrm{MPa}$.

The chemicals employed, $\mathrm{CO}_{2}$ (99.995 vol \% pure), and NMP (Fluka, 98.5 mass \% pure) were used without any further purification. The water was distilled and deionized.

\section{CALCULATION METHODS}

A typical example of absorption/desorption experiment is presented in Fig. 2 where the variations of the system pressure and heat flow rate are plotted versus time. The curves illustrate the pressure decrease and heat generation due to gas absorption, then a rapid decompression via a release valve and a subsequent pressure increase and heat consumption due to gas desorption from the supersaturated liquid. The power dissipated by the stirrer was constant during the experiment and thus could be automati- cally subtracted from the measured heat flow rate as a baseline. Hence, the monitored value of the heat flow rate stands for the absolute value, which corresponds only to the absorption or desorption heat effects.



Figure 2. Time dependence of the pressure $(\mathrm{P})$ and the heat flow rate $(\mathrm{q})$ during the absorption/desorption run in $\mathrm{CO}_{2}$-NMP system at $293.15 \mathrm{~K}$ and the stirring speed of $150 \mathrm{~min}^{-1}$

The $\mathrm{CO}_{2}$ partial pressure in the reactor $\left(\mathrm{p}_{\mathrm{A}}\right)$ was calculated according to the measured total pressure in the system $(\mathrm{P})$ corrected for the solution vapor pressure. The $\mathrm{CO}_{2}$ mass transfer rate $\left(\mathrm{N}_{\mathrm{A}}\right)$ and the actual amount of gas absorbed in the solution were calculated from the pressure values recorded as a function of time using BeattyBridgeman state equation.

The mass balance equation written for the gas component entering the liquid phase predicts a linear dependence of the gas absorption rate and the concentration driving force and has the following form

$\mathrm{N}_{\mathrm{A}, \mathrm{abs}}=\left(\mathrm{k}_{\mathrm{L}} \mathrm{a}\right) \mathrm{V}_{\mathrm{L}}\left(\mathrm{c}_{\mathrm{AL}}^{*}-\mathrm{c}_{\mathrm{AL}}\right)$

where $\mathrm{c}_{\mathrm{AL}}{ }^{*}$ is the concentration of carbon dioxide at the gas-liquid interface and $\mathrm{c}_{\mathrm{AL}}$ is the gas bulk concentration, $\mathrm{V}_{\mathrm{L}}$ stands for the liquid volume, $\mathrm{k}_{\mathrm{L}} \mathrm{a}$ is the volumetric mass transfer coefficient in the liquid phase. The equilibrium concentration $\mathrm{c}_{\mathrm{AL}}{ }^{*}$ is linear related to partial pressure through Henry's law $\left(\mathrm{p}_{\mathrm{A}} / \mathrm{He}\right)$. As the liquid phase was degassed prior to the absorption run, the initial $\mathrm{CO}_{2}$ bulk concentration was assumed to be zero. The actual value of $\mathrm{c}_{\mathrm{AL}}$ could be thus known and determined directly from the amount of the absorbed gas.

For a diffusive (non-bubbling) desorption the similar equation can be written ${ }^{3}$

$\mathrm{N}_{\mathrm{A}, \text { des }}=\left(\mathrm{k}_{\mathrm{L}} \mathrm{a}\right) \mathrm{V}_{\mathrm{L}}\left(\mathrm{c}_{\mathrm{AL}}-\mathrm{c}_{\mathrm{AL}}^{*}\right)=\frac{\left(\mathrm{k}_{\mathrm{L}} \mathrm{a}\right) \mathrm{V}_{\mathrm{L}}}{\mathrm{He}}\left(\mathrm{p}_{\mathrm{A}} \sigma\right)$

In the case of desorption, the actual $\mathrm{CO}_{2}$ bulk and equilibrium concentrations were determined in a similar manner. In these calculations it was assumed that no gas desorption occurs at the short period of time of pressure release under no stirring conditions and thus the initial gas concentration in the desorption run was known and equal to the final (equilibrium) $\mathrm{CO}_{2}$ concentration reached 
in the absorption run. The quantity in Eq. (2) denoted by $\sigma$ is the supersaturation ratio, and is defined as follows $\sigma=\frac{\mathrm{c}_{\mathrm{AL}}}{\mathrm{c}_{\mathrm{AL}}^{*}}-1$

The enthalpies of absorption $\Delta \mathrm{H}_{\mathrm{abs}}$ and desorption $\Delta \mathrm{H}_{\mathrm{des}}$ were determined by the integration of the measured heat flow rate divided by the amount of $\mathrm{CO}_{2}$ absorbed.

\section{RESULTS AND DISCUSSION}

The gas-liquid equilibrium data obtained from several absorption and desorption experiments for $\mathrm{CO}_{2}$-water and $\mathrm{CO}_{2}$-NMP systems are presented in Fig. 3. For $\mathrm{CO}_{2}$-water system, the Henry's constant of $2.67 \mathrm{MPm}^{3} \mathrm{kmol}^{-1}$ was extracted from the solubility curve as the initial slope which is in agreement with the value quoted in the literature $^{5}$. The heat flow measurement during the present experiments allowed the enthalpy of absorption and desorption to be determined. As expected, the absolute values of enthalpies $\Delta \mathrm{H}_{\text {abs }}$ and $\Delta \mathrm{H}_{\text {des }}$ were the same for both processes which supports the validity and accuracy of the experimental method. The percent of difference between the measured absolute value of $\Delta \mathrm{H}_{\mathrm{abs} / \mathrm{des}}=(20.2 \pm 0.3) \mathrm{kJ} \cdot \mathrm{mol}^{-1}$ (an average from several absorption/desorption runs) and a literature reference ${ }^{5}$ of $\Delta \mathrm{H}_{\mathrm{abs}}=-19.9 \mathrm{~kJ} \cdot \mathrm{mol}^{-1}$ is shown to be $1.5 \%$. For $\mathrm{CO}_{2^{-}}$ NMP system, the Henry's constant of $0.64 \mathrm{MPm}^{3} \mathrm{kmol}^{-1}$ and $\Delta \mathrm{H}_{\text {abs/des }}=(14.9 \pm 0.6) \mathrm{kJ} \cdot \mathrm{mol}^{-1}$ were determined.

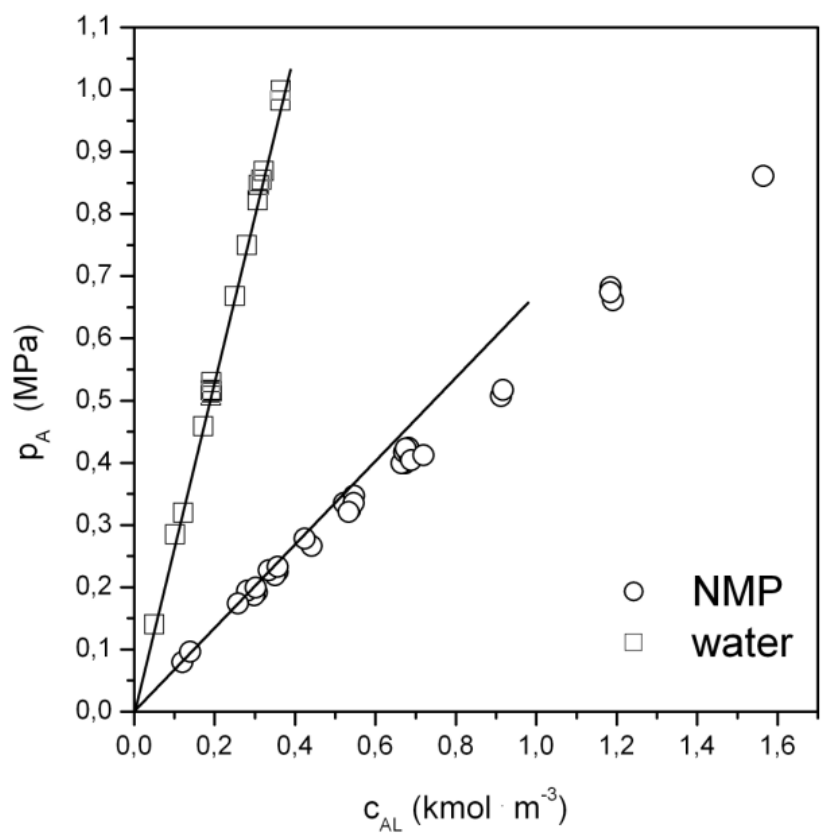

Figure 3. Equilibrium solubility of $\mathrm{CO}_{2}$ in water and NMP solutions at $293.15 \mathrm{~K}$

A typical example of mass transfer rates for $\mathrm{CO}_{2}$ absorption and desorption from the supersaturated NMP solutions is shown in Fig. 4, where both process rates are plotted against the concentration driving force. It can be seen from this figure that the dependence of absorption rate versus the driving force is actually linear as predicted by Eq. (1) with the slope equal to the volumetric mass transfer coefficient in the liquid phase $\mathrm{k}_{\mathrm{L}} \mathrm{a}$. In the case of desorption rate a different trend was observed. As it can be seen, there exist two different regions with respect to the effect of the driving force. In the initial stage of desorption run which corresponds to the high values of the supersaturation ratio, the desorption rate deviates upward from the absorption rate, represented by the straight line. In this region the bubble nucleation was visually observed through the glass walls of the reactor. The bubble nucleation in the liquid phase increases the turbulence in that phase and results in a subsequent increase of the mass transfer coefficient and the interfacial area. The observed rate of desorption under bubbling conditions is significantly greater than the absorption rate for the same driving force. This observation is in agreement with the previous findings ${ }^{3-4}$. Then as the supersaturation decreases while approaching to equilibrium state, the $\mathrm{CO}_{2}$ desorption rate clearly decreases and becomes equal to the absorption rate. Under non-bubbling conditions the rate of desorption can be well represented as a linear function of driving force and the volumetric mass transfer coefficient $\mathrm{k}_{\mathrm{L}}$ a determined from the desorption run is the same as that obtained from the absorption run at a given stirring speed. In this region designated as diffusive or quiescent desorption, the mass transfer takes place by a diffusive mechanism and the absorption model can be successfully used to predict the desorption rates. The transition point from bubbling to quiescent desorption corresponds to a certain value of the supersaturation ratio termed as critical and is designated by $\sigma_{\text {crit }}$.

However, the inception of bubbling is not sharp and takes place smoothly as evidenced by other results presented in Fig. 5 which illustrates the desorption rate data plotted as a function of $\left(\sigma \mathrm{p}_{\mathrm{A}}\right)$ obtained from various experiments at the same stirring speed but different initial supersaturation ratio. In this figure, the desorption rate predicted from Eq. (2) is plotted for the comparison. Figure 5 shows clearly the influence of the instantaneous supersaturation ratio and pressure on the rate of desorption. From the presented data, the transition point from bubbling to diffusive desorption was found to correspond to

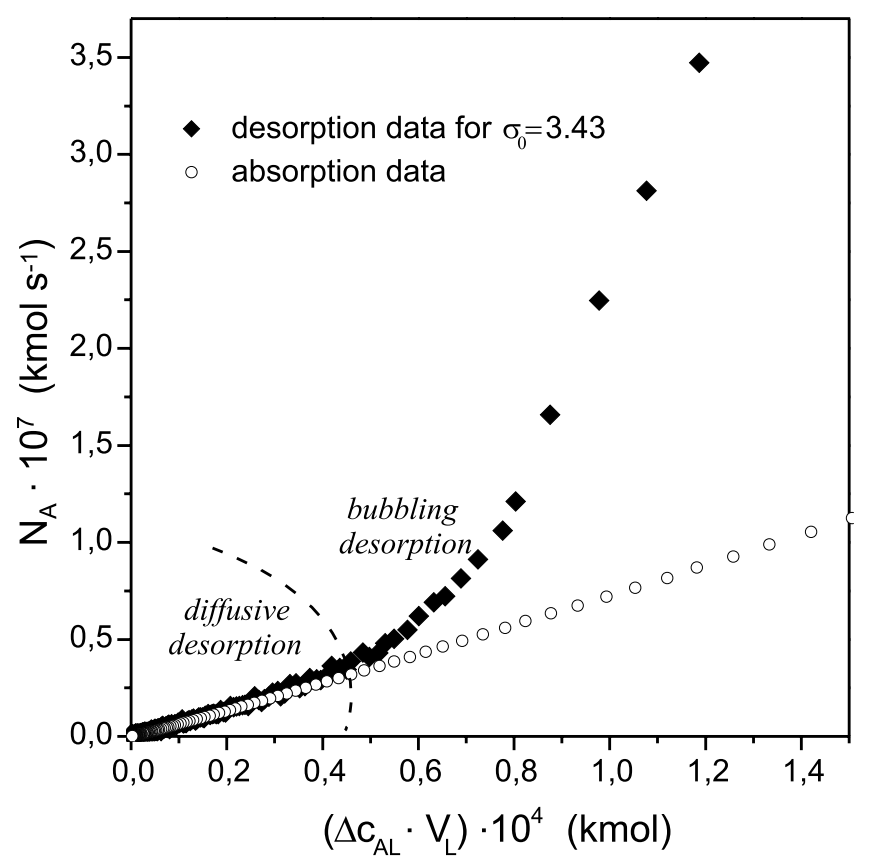

Figure 4. Typical $\mathrm{CO}_{2}$ absorption and desorption rates against the concentration driving force for a stirring speed of $150 \mathrm{~min}^{-1}$ 




Figure 5. Measured and predicted non-bubbling desorption rates versus $\left(\sigma \cdot p_{A}\right)$ for a stirring speed of $250 \mathrm{~min}^{-1}$

$\left(\sigma \cdot p_{A}\right) \cong 0.2 \mathrm{MPa}$ for all three runs . From this value, the critical supersaturation ratio scrit can be subtracted for a given pressure. However, while plotting the same relationships for the experimental data obtained at other stirring speeds of 150 and $250 \mathrm{~min}^{-1}$, it was found that the value of $\left(\sigma \cdot p_{A}\right)$ which corresponds to the transition between bubbling and diffusive desorption, decreased slightly with increasing the stirring speed. Therefore, the resulting critical supersaturation ratio scrit was lower for the stirring speed of $250 \mathrm{~min}^{-1}$ than for 200 and $150 \mathrm{~min}^{-1}$ for the same pressure. In other words, the increased turbulence in the system enhances the desorption rate and causes a lowering of the threshold for bubbling desorption. The results of $\sigma_{\text {crit }}$ as a function of pressure extracted from present measurements at various stirring speeds are plotted in Fig. 6. The effect of stirring speed is to promote bubble heterogeneous nucleation. This is because, for higher stirring speed, the bubbles find it easier to detach themselves from the walls of the vessel and its bottom.

\section{CONCLUSIONS}

The rates of $\mathrm{CO}_{2}$ desorption from the supersaturated NMP solutions were investigated at $293.15 \mathrm{~K}$ using the laboratory reaction calorimeter. The measurements were based on a batch isothermal absorption in the agitated vessel and a subsequent desorption, which was initialized by the pressure release in the system. Based on the measured values of pressure change, the desorption rate was determined and compared to the absorption rate at the same driving force.

The obtained results show that the $\mathrm{CO}_{2}$ desorption rate increases with increasing the supersaturation ratio, pressure and the stirring speed. In the non-bubbling region of the process, the desorption process can be regarded as a reverse one to the absorption one. The desorption rate under bubbling conditions was significantly greater than the absorption rate for the same driving force The critical supersaturation ratio was found to decrease with increasing the pressure and the stirring speed. The present find-

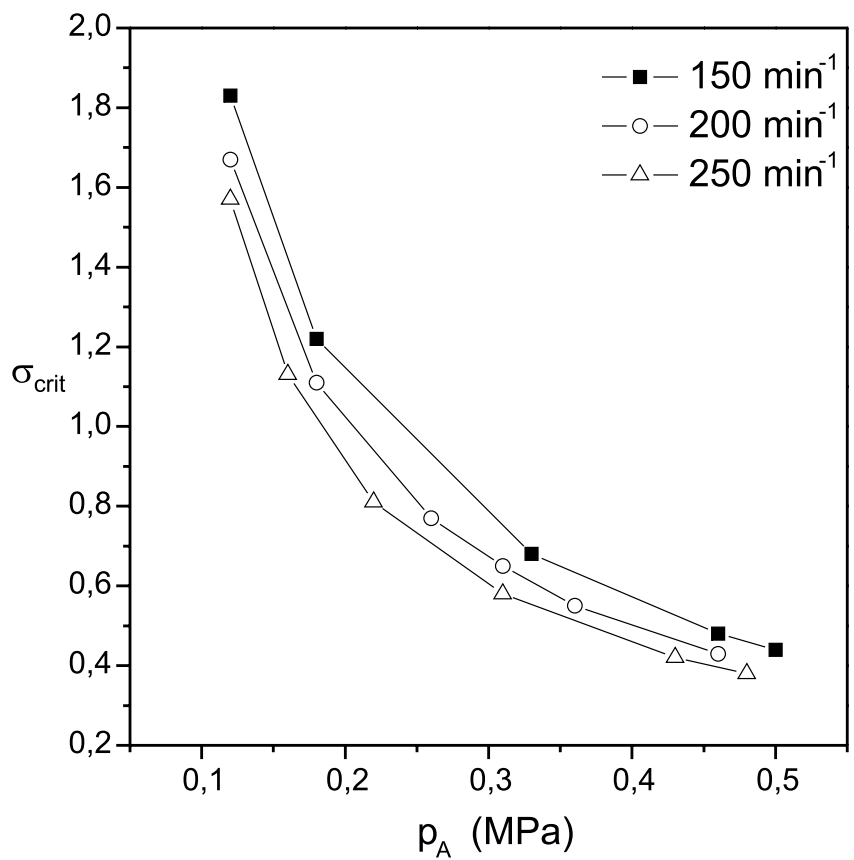

Figure 6. Critical supersaturation ratio scrit as a function of pressure and the stirring speed for $\mathrm{CO}_{2}$ desorption from the supersaturated NMP solutions at $293.15 \mathrm{~K}$

ing would be helpful for the design considerations of the regeneration step in several industrial processes for separating $\mathrm{CO}_{2}$ based on physical solvents. Although this study has provided an improved understanding of the desorption process, the issues related to the quantitative description of the desorption kinetics under bubbling conditions need to be studied further.

\section{ACKNOWLEDGMENT}

This work was funded by the Ministry of Science and Higher Education of Poland (Project No. 1 T09C 018 $30)$.

\section{LITERATURE CITED}

(1) Kohl A., Nielsen R.: Gas Purification, 5 ${ }^{\text {th }}$ ed.; Gulf Publishing Co.: Houston, TX, 1997.

(2) Lubetkin S. D.: Why Is It Much Easier To Nucleate Gas Bubbles than Theory Predicts?, Langmuir, 2003, 19, 2575.

(3) Weiland R. H., Thuy L. T., Liveris A. N.: Transition from Bubbling to Quiescent Desorption of Dissolved Gases, Ind. Eng. Chem. Fund., 1977, 16 (3), 332.

(4) Hikita H., Konishi Y.: Desorption of Carbon Dioxide from Supersaturated Water in an Agitated Vessel, AIChE J., 1984, 30 (6), 945.

(5) Ullmann's Encyclopedia of Industrial Chemistry, $4^{\text {th }}$ ed., Vol. 2, Verlag Chemie: Weinheim, 1984. 